This item was submitted to Loughborough's Research Repository by the author.

Items in Figshare are protected by copyright, with all rights reserved, unless otherwise indicated.

\title{
Insights into the mechanism of Nitrobenzene reduction to aniline over Pt catalyst and the significance of the adsorption of phenyl group on kinetics
}

PLEASE CITE THE PUBLISHED VERSION

http://dx.doi.org/10.1016/j.cej.2016.02.066

\section{VERSION}

AM (Accepted Manuscript)

\section{PUBLISHER STATEMENT}

This work is made available according to the conditions of the Creative Commons Attribution-NonCommercialNoDerivatives 4.0 International (CC BY-NC-ND 4.0) licence. Full details of this licence are available at: https://creativecommons.org/licenses/by-nc-nd/4.0/

\section{LICENCE}

CC BY-NC-ND 4.0

\section{REPOSITORY RECORD}

Sheng, Tian, Yi-Jun Qi, Xiao Lin, Peijun Hu, Shi-Gang Sun, and Wen-Feng Lin. 2016. "Insights into the Mechanism of Nitrobenzene Reduction to Aniline over Pt Catalyst and the Significance of the Adsorption of Phenyl Group on Kinetics". figshare. https://hdl.handle.net/2134/20541. 


\title{
Insights into the Mechanism of Nitrobenzene Reduction to Aniline over Pt \\ Catalyst and the Significance of the Adsorption of Phenyl Group on
} Kinetics

Tian Sheng a,b ${ }^{\mathrm{a}}$, Yi-Jun Qi ${ }^{\mathrm{a}}$, Xiao Lin ${ }^{\mathrm{a}, \mathrm{c}}$, P. Hu ${ }^{\mathrm{a}}$, Shi-Gang Sun ${ }^{\mathrm{b}}$, Wen-Feng Lin ${ }^{\mathrm{a}, \mathrm{d},{ }^{*}}$

${ }^{a}$ Centre for the Theory and Application of Catalysis, School of Chemistry and Chemical Engineering, Queen's University of Belfast, Belfast BT9 5AG, U.K.

${ }^{\mathrm{b}}$ Collaborative Innovation Center of Chemistry for Energy Materials, State Key Laboratory of Physical Chemistry of Solid Surfaces, College of Chemistry and Chemical Engineering, Xiamen University, Xiamen, 361005, China

${ }^{c}$ Department of Chemical Engineering and Biotechnology, University of Cambridge, Cambridge CB2 3RA, U.K.

d Department of Chemical Engineering, Loughborough University, Loughborough, Leicestershire, LE11 3TU, U.K.

\begin{abstract}
Aniline $\left(\mathrm{C}_{6} \mathrm{H}_{5} \mathrm{NH}_{2}\right)$ plays a significant role in both industry and daily life, and can be synthesized via catalytic hydrogenation of nitrobenzene $\left(\mathrm{C}_{6} \mathrm{H}_{5} \mathrm{NO}_{2}\right)$ over transition metals; however fundamental investigations on reaction mechanisms in the heterogeneous catalysis are still lacking. In this work, the nitrobenzene reduction reaction over the $\operatorname{Pt}(111)$ model catalyst was studied using density functional theory (DFT) with the inclusion of van der Waals interaction, for fundamentally understanding the mechanisms at atomic and molecular levels. It was found that the double $\mathrm{H}$-induced dissociation of $\mathrm{N}-\mathrm{O}$ bond was the preferential path for the activation of nitro group, having a much lower reaction barrier than that of the direct dissociation and single $\mathrm{H}$-induced dissociation paths. The overall mechanisms have been identified as: $\mathrm{C}_{6} \mathrm{H}_{5} \mathrm{NO}_{2} * \rightarrow \mathrm{C}_{6} \mathrm{H}_{5} \mathrm{NOOH}^{*} \rightarrow \mathrm{C}_{6} \mathrm{H}_{5} \mathrm{~N}(\mathrm{OH})_{2} * \rightarrow \mathrm{C}_{6} \mathrm{H}_{5} \mathrm{NOH}^{*} \rightarrow$ $\mathrm{C}_{6} \mathrm{H}_{5} \mathrm{NHOH}^{*} \rightarrow \mathrm{C}_{6} \mathrm{H}_{5} \mathrm{NH}^{*} \rightarrow \mathrm{C}_{6} \mathrm{H}_{5} \mathrm{NH}_{2} *$. The overall barrier of the nitro group reduction was calculated to be $0.75 \mathrm{eV}$, which is much lower than that of the benzene reduction $(1.08$
\end{abstract}


$\mathrm{eV}$ ). Our DFT data elucidates clearly the reason why the major product of nitrobenzene reduction reaction was aniline. Furthermore, the adsorption/desorption of phenyl group was found to have significant impacts on kinetic barriers. Generally, in the hydrogenation process ( $\mathrm{N}-\mathrm{H}$ or $\mathrm{O}-\mathrm{H}$ bond association), the phenyl group preferred to adsorb on the surface; but in the dissociation process ( $\mathrm{N}-\mathrm{O}$ bond dissociation) it preferred to desorb transiently at the transition state and to adsorb again when the dissociation was completed. This study also provides a solid theoretical insight into the selective catalysis of the large aromatic compounds.

*Corresponding author at: Department of Chemical Engineering, Loughborough University, Loughborough, Leicestershire, LE11 3TU, U.K. (W. F. Lin)

E-mail: w.lin@lboro.ac.uk (W. F. Lin)

Keywords: hydrogenation; deoxygenation; van der Waals interaction; selectivity; density functional theory; heterogeneous catalysis; 


\section{Introduction}

Aniline $\left(\mathrm{C}_{6} \mathrm{H}_{5} \mathrm{NH}_{2}\right)$ is an important chemical raw material, which is widely used in the rubber, fine chemicals (dyes and pigments), agrochemical (pesticides and herbicides) and pharmaceutical industry [1-13]. Aniline is manufactured via catalytic hydrogenation of nitrobenzene $\left(\mathrm{C}_{6} \mathrm{H}_{5} \mathrm{NO}_{2}\right)$ over a series of transitional metal catalysts such as $\mathrm{Pd}, \mathrm{Pt}, \mathrm{Ni}, \mathrm{Cu}$, $\mathrm{Ru}$ and $\mathrm{Au}$, at various conditions, e.g., gas-phase or liquid-phase hydrogenation, as well as electrochemical reduction [1-13]. In the catalytic hydrogenation of nitrobenzene, the nitro group is usually reduced to amino group but the phenyl group remains [1-13]. A wide range of catalysts for reduction of nitrobenzene to aniline have been studied experimentally. Among them, noble Pt and Pd based catalysts were identified to be highly effective under modest conditions [6,10,14-20]. Most of the investigations have been focused on the catalytic performance but not on the mechanisms. The mechanisms of the nitrobenzene reduction are complicated and the reaction environments could play significant roles, for instance, the products are different under acidic, neutral and alkaline electrochemical conditions [2,4]. Gelder et al. and Corma et al. proposed some insights into the mechanisms in the nitrobenzene reduction [12,13]. In fact, with respect to the aromatic compounds having multiple functional groups, the selectivity towards the desired functional group reaction is a big challenge in heterogeneous catalysis. For example, in the reduction of halonitrobenzene, to achieve a selective hydrogenation to haloaniline but avoiding the occurrence of dehalogenation requires a precise design of highly selective catalysts [14-20]. It is essential to get a deep understanding of the possible reaction mechanisms to enable us to achieve the selective catalysis.

In the recent years, density functional theory (DFT) calculations have been widely employed to understand the surface catalytic reactions at the atomic and molecular levels. To model the mechanism of nitrobenzene reduction, there are two significant problems to overcome. The first challenge is associated with the large size of nitrobenzene molecule, because a larger molecule would considerably increase the number of possible adsorption configurations [21-32], therefore, a significantly more adsorption configurations should be carefully tested in the calculations of nitrobenzene, in contrast to the much fewer adsorption configurations of 
other smaller organic molecules such as formic acid or methanol. In addition, an increase in adsorption configurations would also lead to an increase in the numbers of possible transition states, which again makes the calculations more complicated and time-consuming [21,22]. The second challenge is associated with the fact that, in the case of weak overlap of electrons/orbitals between the phenyl group and the metal surface, the van der Waals (vdW) interaction is frequently the only force that brings and binds the molecule to the surface [23-25]; the influences of vdW interaction on the large aromatic compounds concerning adsorption, energetics or kinetics, are still less well documented in heterogeneous catalysis. Only a few pioneering works have been made in the study of these large molecules [21,22,26-32]. Saeys et al. calculated benzene adsorption and hydrogenation to cyclohexane on $\operatorname{Pt}(111)$ [21,22]. Mahata et al. reported the mechanism of nitrobenzene reduction over $\mathrm{Ni}(111)$ via direct or indirect mechanisms [26]. With respect to some other large molecules in heterogeneous catalysis, Lu et al. systematically calculated the hydrogenation of guaiacol over $\mathrm{Ru}(0001)$ and $\mathrm{Pt}(111)$ surfaces involving the C-O bond dissociation [28,29]. Wang et al. studied the activity and selectivity between hydrogenation and decarbonylation of furan and its derivatives on $\operatorname{Pd}(111)$ [30,31]. These studies have provided some initial insights into the surface chemistry of large molecules in heterogeneous catalysis. Despite of extensive experimental studies, there is still lacking theoretical work to elucidate the mechanism of nitrobenzene reduction over platinum catalysts.

In order to provide a better understanding of the nitrobenzene reduction to aniline over platinum catalyst, we have systematically investigated the mechanism using first principle calculations with the inclusion of vdW interactions, for the first time. The closed-packed flat Pt(111) surface as the thermodynamically most stable facet was used here as an ideal model catalyst for calculations. This paper is organised as follows. The computational method is described in section 2. The calculated results, including the adsorption of nitrobenzene and aniline, and the hydrogenation and deoxygenation mechanisms of the nitro group, are shown in sections 3.1 and 3.2. Then the influence of the adsorption of phenyl group at the transition state on both the kinetic barriers and the selective catalysis is further discussed in sections 3.3 and 3.4. Finally, the main conclusions are summarized. We anticipate this work would be of 
benefit for the further study of large aromatic compounds in heterogeneous catalysis, molecular engineering and environmental engineering.

\section{Computational methods}

All the DFT calculations were implemented with the Perdew-Burke-Ernzerh (PBE) generalized gradient approximation (GGA) exchange-correlation functional using the Vienna Ab-initio Simulation Package (VASP) code [33-39]. The projector-augmented-wave (PAW) pseudopotentials were utilized to describe the core electron interaction. Since the exclusion of the vdW interactions in the strongly adsorbed benzene on metals would lead to a significant reduction in the adsorption energy from PBE, the optB88-vdW method as implemented in the VASP code was utilized to describe vdW interactions [23-25]. The cut-off energy was set to $400 \mathrm{eV}$ which was tested to be accurate enough for energy calculations. The vacuum region layers were built more than $12 \AA$ to ensure the slab interaction was eliminated. A $p(3 \times 3)$ supercell was used with 3x3x1 Monkhorst-Pack $k$-point sampling for Brillouin zone. The size of supercell agrees with the experimental observation of the benzene coverage [40,41]. During all the optimization process, the bottom half atoms were fixed in the slab while the top half atoms were relaxed. All the transition states were localized with constrained minimization approach and the convergence of forces was set to $0.05 \mathrm{eV} / \AA$ [42-44]. In this work, the adsorption energy was defined as: $\mathrm{E}_{\mathrm{ad}}=\mathrm{E}(\mathrm{ad} / \mathrm{Pt})-\mathrm{E}(\mathrm{ad})-\mathrm{E}(\mathrm{Pt})$, where $\mathrm{E}(\mathrm{ad} / \mathrm{Pt})$, $\mathrm{E}(\mathrm{ad})$, and $\mathrm{E}(\mathrm{Pt})$ are the total energies of the adsorbate binding to $\mathrm{Pt}(111)$ surface, free adsorbate in gas phase and clean $\operatorname{Pt}(111)$, respectively.

\section{Results and discussions}

\subsection{Nitrobenzene and aniline adsorption}

Experimentally, over a range of catalysts studied, only nitro- group of nitrobenzene was reduced to amino group whilst the phenyl group held, therefore we concentrated on the reduction mechanism of nitro- group in this theoretical study [1-13]. In the surface catalytic reactions, the first stage was the adsorption of nitrobenzene on the $\operatorname{Pt}(111)$ surface. It is worth emphasising that both the phenyl- and nitro- groups are reactive towards binding to Pt surface free sites, and thus the considerations of the adsorption via the phenyl- and nitro- groups are 
necessary. Firstly, we calculated the adsorption of nitrobenzene via the phenyl group, specifically the centre of the phenyl group was located at the top, bridge and hollow sites, respectively, on $\operatorname{Pt}(111)$ surface as the initial structures and then the geometry optimizations were performed.

When phenyl group was located at the Pt top site, nitrobenzene spontaneously desorbed during the optimization since no chemical bonds were formed between the nitrobenzene and Pt(111) surface. It was found that nitrobenzene stayed parallel above the surface with a height of $\sim 3.5 \AA$ as shown in Figure 1a. Despite of the relative long distance between nitrobenzene and the surface, the adsorption energy calculated is $-1.06 \mathrm{eV}$, indicating the interaction between nitrobenzene and the Pt surface is actually considerably strong. We conclude that the vdW interaction might make the vital contribution here though the weak overlap of electrons/ orbitals between the phenyl group and $\mathrm{Pt}(111)$ surface could also exist. If without consideration of vdW interaction in the calculation, the adsorption energy was lowered to a minute value $(-0.15 \mathrm{eV})$, implying that there is no occurrence of nitrobenzene adsorption, in agreement with the parallel configuration. Therefore, in this case, the vdW interaction is considered as the main force for binding nitrobenzene to the $\operatorname{Pt}(111)$ surface, i.e., physisorption dominates [23].

In contrast, Figures 1b and 1c show the optimized structures of nitrobenzene adsorbed at the bridge and hollow sites, respectively. It was found that the phenyl group could adsorb on the surface via the formation of C-Pt bonds: all of the five $\mathrm{C}-\mathrm{H}$ bonds were tilted out of the phenyl plane, aroused from the strong overlapping of the partially empty d-band of Pt with the $\mathrm{p}_{z}$ orbitals of phenyl group [21]. Such a strong interaction between phenyl group and $\operatorname{Pt}(111)$ resulted in the rehybridization of the carbon orbitals from $\mathrm{sp}^{2}$ to $\mathrm{sp}^{3}$ and as a consequence, chemisorption dominated. For the bridging bonded nitrobenzene as shown in Figure 1b, all of the six $\mathrm{C}$ atoms of phenyl group were bound to four $\mathrm{Pt}$ atoms. The adsorption energy was calculated to be $-1.71 \mathrm{eV}$. Remarkably, this significantly increased binding energy was caused by the chemisorption of phenyl group in comparison with the only physisorption situation shown in Figure 1a $(-1.06 \mathrm{eV})$. The bridge site is the so-called bri30 
adsorption site reported in the previous study of benzene adsorption since the angle between the $\mathrm{C}-\mathrm{C}$ bond and the Pt-Pt bond is $30^{\circ}$ [21-23]. At the hollow site, the $\alpha-\mathrm{C}$ binding to the nitro- group was dangling above the surface while the other five $\mathrm{C}$ atoms did bind to Pt sites, yielding the adsorption energy of $-1.52 \mathrm{eV}$ which is slightly lower than that $(-1.71 \mathrm{eV})$ at the bri $30^{\circ}$ site. It is worth mentioning that we have examined both the two hollow sites of fcc and hcp types, and found that virtually there was no difference (below $0.01 \mathrm{eV}$ ) in terms of the adsorption energy, therefore, only fcc hollow site is considered in the following analysis.

On the other hand, if the nitro- group adsorbed via the two $\mathrm{O}$ ends at the two neighbouring Pt sites, the phenyl group would adsorb vertically to the Pt(111) plane, as shown in Figure 1d. The average distance of Pt-O bond would be $2.27 \AA$ with the calculated adsorption energy being $-0.66 \mathrm{eV}$, the latter is even lower than the aforementioned physisorption one $(-1.06 \mathrm{eV})$. The rationale behind this data could be that since the phenyl group adsorbed vertically, the overlap of the electrons/orbitals between phenyl group and the Pt surface was very limited and as a result, a partially loss of vdW interaction would make nitrobenzene unfavourable to adsorb via nitro- group. Overall, the above data illustrates that, despite of the presence of nitro- group the most preferential adsorbing mode for nitrobenzene is via phenyl group on the bri30 ${ }^{\circ}$ site as shown in Figure 1b. This is, in fact, consistent with the adsorption of benzene on $\operatorname{Pt}(111)$ [21,22]. It was worth noticing that our result is different from that in ref [32], where the phenyl group of nitrobenzene adsorbed vertically on the surface during the reaction. This difference is mainly because the vdW interactions were not considered in ref [32]. However, it has been reported that, for the phenyl group, the vdW interaction has a significant influence on the adsorption at metal surfaces [21-23].

For the adsorption of aniline, the physisorption state was not observed. The $\mathrm{N}$ atom of amino group would spontaneously adsorb at the top site of Pt(111) surface via the N-Pt bonding, of which the distance being $2.22 \AA$ with an adsorption energy of $-1.46 \mathrm{eV}$. The optimized structure is shown in Figure 2a, where the lone pair electrons of the $\mathrm{N}$ atom have a strong tendency to bind to the surface. However, if the phenyl group moved to the vertical position as shown in Figure 2d, the adsorption energy would decrease to $-1.03 \mathrm{eV}$, indicating that the 
vdW interaction between the vertically positioned benzene ring and the Pt surface would be weaker than the parallel one. Interestingly, unlike nitrobenzene, aniline adsorbed equally well at the bri30 and hollow site (as shown in Figure $\mathbf{2 b}$ and $2 \mathbf{c}$, respectively), yielding the same adsorption energy of $-1.66 \mathrm{eV}$.
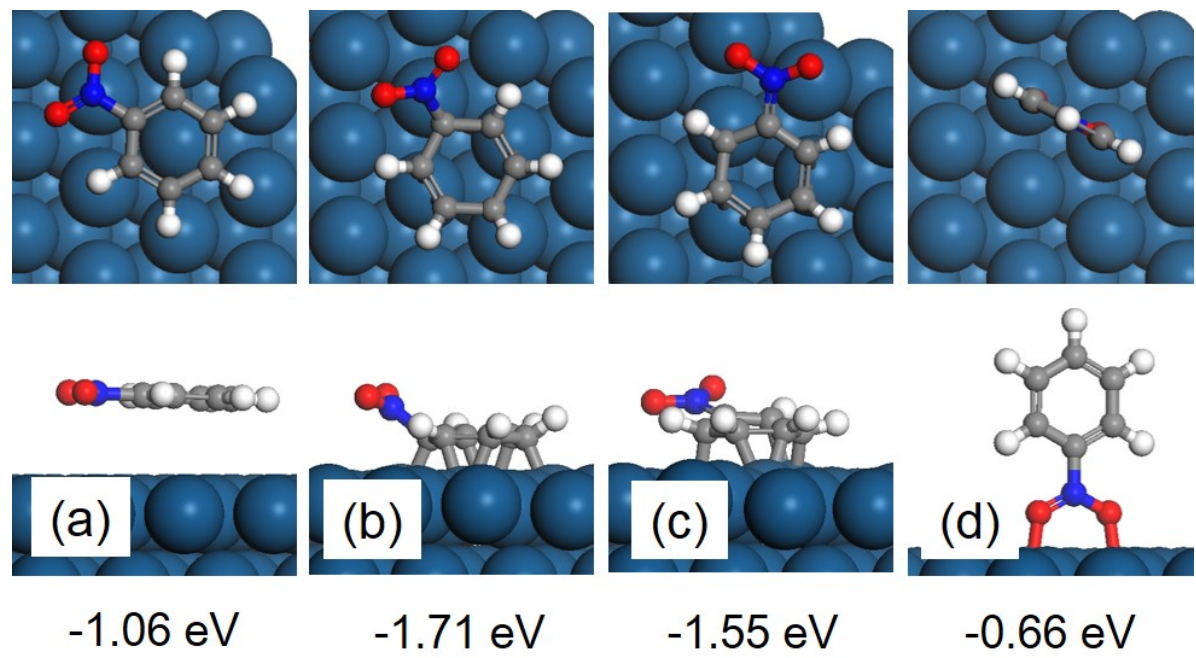

$-1.55 \mathrm{eV}$

$-0.66 \mathrm{eV}$

Fig. 1. Top and side views of the four optimized configurations of adsorbed nitrobenzene $\left(\mathrm{C}_{6} \mathrm{H}_{5} \mathrm{NO}_{2}{ }^{*}\right)$ on the Pt(111) surface, together with the corresponding adsorption energies indicated. Blue: Pt, red: O, grey: C, white: H, dark blue: N. (The same colours are used throughout the paper.)
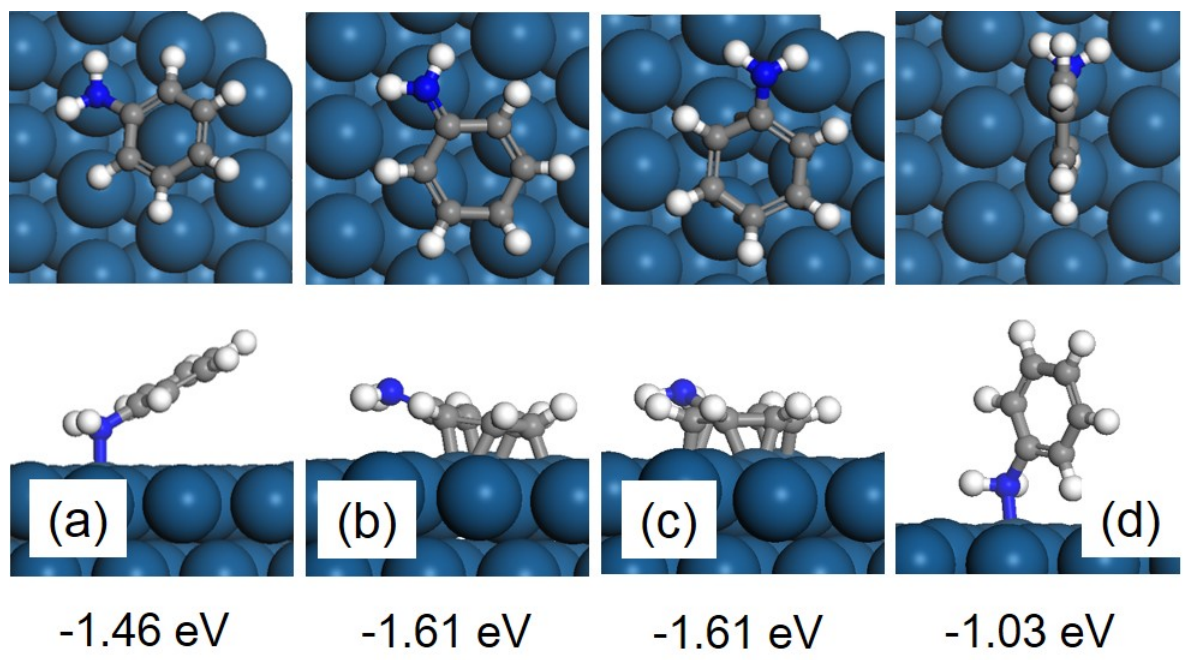

$-1.61 \mathrm{eV}$

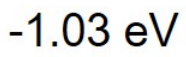

Fig. 2. Top and side views of the four optimized configurations of adsorbed aniline $\left(\mathrm{C}_{6} \mathrm{H}_{5} \mathrm{NH}_{2}{ }^{*}\right)$ on the Pt(111) surface, together with the corresponding adsorption energies indicated. 


\subsection{Mechanism of nitrobenzene reduction to aniline}

During the nitrobenzene reduction to aniline process, two $\mathrm{N}-\mathrm{O}$ bonds were broken and the produced oxygen-species $\left(\mathrm{OH}^{*}\right.$ or $\left.\mathrm{O}^{*}\right)$ were reduced to water as by-products. The energy profiles are presented in Figure 3 and the corresponding structures of intermediates and transition states are shown in Figure 4. Two feasible pathways, i.e., (i) direct dissociation and (ii) indirect hydrogen-induced dissociation, may be taken into account in the deoxygenation $[45,46]$. Therefore, we have examined both paths to get insights into the detailed mechanisms, as well as to identify which one would be more likely for the $\mathrm{N}-\mathrm{O}$ bond dissociation.

For the direct dissociation path (i), $\mathrm{C}_{6} \mathrm{H}_{5} \mathrm{NO}_{2} * \rightarrow \mathrm{C}_{6} \mathrm{H}_{5} \mathrm{NO}^{*}+\mathrm{O}^{*}$, the calculated reaction energy is $0.09 \mathrm{eV}$, indicating that this path is unfavourable in thermodynamics. Moreover, a high barrier of $1.61 \mathrm{eV}$ needs to overcome, suggesting that a direct breaking of $\mathrm{N}-\mathrm{O}$ bond is strongly prohibited in kinetics. For the indirect path (ii), the $\mathrm{O}$ of $\mathrm{N}-\mathrm{O}$ bond was firstly hydrogenated to activate the strong $\mathrm{N}-\mathrm{O}$ bond and then to facilitate the subsequent $\mathrm{N}-\mathrm{O}$ bond dissociation. The barrier of $\mathrm{H}^{*}$ attacking the $\mathrm{O}$ was calculated to be $0.35 \mathrm{eV}$, with the $\mathrm{O}-\mathrm{H}$ bond length at the TS1 being $1.41 \AA$. This elementary step, as shown in the reaction 1 below, is slightly endothermic of $0.06 \mathrm{eV}$.

$$
\mathrm{C}_{6} \mathrm{H}_{5} \mathrm{NO}_{2}^{*}+\mathrm{H}^{*} \rightarrow \mathrm{C}_{6} \mathrm{H}_{5} \mathrm{NOOH}^{*}
$$

After the N-O bond being hydrogenated, the distance of N-O bond was elongated from 1.246 $\AA$ to $1.436 \AA$, indicating that the $\mathrm{N}-\mathrm{O}$ bond had already been activated by the $\mathrm{H}$ atom. The most stable structure of the $\mathrm{C}_{6} \mathrm{H}_{5} \mathrm{NOOH}^{*}$ was the $\mathrm{H}$-down of $\mathrm{OH}$ group configuration, which was $0.10 \mathrm{eV}$ more stable than the $\mathrm{H}$-up configuration. The decomposition barrier of $\mathrm{C}_{6} \mathrm{H}_{5} \mathrm{NOOH}^{*}$ to yield $\mathrm{C}_{6} \mathrm{H}_{5} \mathrm{NO}^{*}$ and $\mathrm{OH}^{*}, \mathrm{C}_{6} \mathrm{H}_{5} \mathrm{NOOH}^{*} \rightarrow \mathrm{C}_{6} \mathrm{H}_{5} \mathrm{NO}^{*}+\mathrm{OH}^{*}$, was $1.05 \mathrm{eV}$ that is much lower than $1.61 \mathrm{eV}$ of the direct path, and the corresponding reaction energy was $-0.03 \mathrm{eV}$, being slightly exothermic.

Although the indirect $\mathrm{H}$-induced path would noticeably facilitate the deoxygenation in comparison with the direct path $(1.05 \mathrm{eV}$ vs $1.61 \mathrm{eV})$, the high barrier of $1.05 \mathrm{eV}$ still indicates that this step would be difficult to occur. In this case, we noticed that the other $\mathrm{O}$ of 
the nitro group could be further hydrogenated and therefore, another feasible path was examined: namely (iii) double $\mathrm{H}$-induced dissociation in which the nitro group was doubly hydrogenated to $\mathrm{N}(\mathrm{OH})_{2}$ group before the dissociation to occur. The third path could be written as reactions 2 and 3 below.

$$
\begin{aligned}
& \mathrm{C}_{6} \mathrm{H}_{5} \mathrm{NOOH}^{*}+\mathrm{H}^{*} \rightarrow \mathrm{C}_{6} \mathrm{H}_{5} \mathrm{~N}(\mathrm{OH})_{2}{ }^{*} \\
& \mathrm{C}_{6} \mathrm{H}_{5} \mathrm{~N}(\mathrm{OH})_{2}{ }^{*} \rightarrow \mathrm{C}_{6} \mathrm{H}_{5} \mathrm{NOH}^{*}+\mathrm{OH}^{*}
\end{aligned}
$$

It was found that the barrier for the second $\mathrm{H}^{*}$ transferred to nitro group being small $(0.27$ $\mathrm{eV}$ ), yielding the $\mathrm{O}-\mathrm{H}$ bond length of $1.43 \AA$ at the TS2. Although the reaction 2 is a little endothermic of $0.23 \mathrm{eV}$ which is not thermodynamically favoured, the new formed $\mathrm{C}_{6} \mathrm{H}_{5} \mathrm{~N}(\mathrm{OH})_{2}$ * was identified to be an active intermediate. After double hydrogenation of nitro group, the dangling $\mathrm{N}$ atom started to adsorb at the Pt surface site with the $\mathrm{H}$-down configuration. The N-O bond of $\mathrm{C}_{6} \mathrm{H}_{5} \mathrm{~N}(\mathrm{OH})_{2}$ * was found to be highly activated with only a small barrier of $0.46 \mathrm{eV}$, resulting in the formation of $\mathrm{C}_{6} \mathrm{H}_{5} \mathrm{NOH}^{*}$ and $\mathrm{OH}^{*}$ on the Pt surface. The N-O bond distance was lengthened to $1.73 \AA$ at the TS3. This elementary step was found to be highly exothermic of $-0.68 \mathrm{eV}$, and the produced $\mathrm{OH}^{*}$ group would be readily reduced to $\mathrm{H}_{2} \mathrm{O}^{*}$ with the exothermic of $-0.77 \mathrm{eV}$. As a by-product, $\mathrm{H}_{2} \mathrm{O}^{*}$ weakly adsorbed at the $\mathrm{Pt}$ top site with a low adsorption energy of $-0.42 \mathrm{eV}$, indicating that water would easily desorb upon formation. The overall barrier in the double $\mathrm{H}$-induced dissociation path was found to be $0.75 \mathrm{eV}$, from $\mathrm{C}_{6} \mathrm{H}_{5} \mathrm{NO}_{2} *$ to TS3 as highlighted in Figure 3. In comparison with the direct dissociation path (i) of which the activation energy being $1.61 \mathrm{eV}$ and the single $\mathrm{H}$-induced dissociation path (ii) of which the overall barrier being $1.09 \mathrm{eV}$, the double $\mathrm{H}$-induced dissociation path was identified to be the most preferential one with the lowest overall barrier of $0.75 \mathrm{eV}$, which could be feasible at room temperature. In comparison with the $\mathrm{N}-\mathrm{O}$ bond dissociation mechanism reported on the $\mathrm{Ni}(111)$ surface in ref [26], where $\mathrm{C}_{6} \mathrm{H}_{5} \mathrm{NOOH}^{*}$ was found to be the precursor, here on the $\mathrm{Pt}(111)$ surface, $\mathrm{C}_{6} \mathrm{H}_{5} \mathrm{~N}(\mathrm{OH})_{2}$ * was identified to be the most likely precursor. The main reason for this difference is due to the fact that $\mathrm{Ni}$ and $\mathrm{Pt}$ have different inherent reactivity and $\mathrm{Ni}$ is actually more active than Pt for this reaction. Therefore, for Pt(111), the double H-induced path which would make the N-O bond more reactive, was required to lower the dissociation barrier to a reasonable value to enable the 
reaction to be feasible; however, for $\mathrm{Ni}(111)$, the single $\mathrm{H}$-induced path was already energetically favorable.

Once $\mathrm{C}_{6} \mathrm{H}_{5} \mathrm{NOH}^{*}$ was produced on surface, the $\mathrm{N}-\mathrm{H}$ bond association would readily occur as shown in the reaction 4 below, yielding $\mathrm{C}_{6} \mathrm{H}_{5} \mathrm{NHOH}^{*}$ of which the reaction energy was downhill of $-0.45 \mathrm{eV}$. A slight hydrogenation barrier of $0.15 \mathrm{eV}$ was found, with the $\mathrm{N}-\mathrm{H}$ bond length of $1.57 \AA$ at the TS4. In the reaction 5 (see below), to yield $\mathrm{C}_{6} \mathrm{H}_{5} \mathrm{NH}^{*}$ and to produce the second $\mathrm{OH}^{*}$, the $\mathrm{N}-\mathrm{O}$ bond dissociation barrier in $\mathrm{C}_{6} \mathrm{H}_{5} \mathrm{NHOH}^{*}$ was calculated to be $0.66 \mathrm{eV}$, with the N-O bond distance of $1.78 \AA$ at the TS5. This dissociation step was shown to be highly exothermic of $-0.89 \mathrm{eV}$. Finally, after the last $\mathrm{H}^{*}$ transferring to $\mathrm{C}_{6} \mathrm{H}_{5} \mathrm{NH}^{*}$ as shown in the reaction 6 (see below), the complete reduction of nitrobenzene to aniline was achieved. The barrier for the $\mathrm{N}-\mathrm{H}$ bond formation was $0.60 \mathrm{eV}$, with the $\mathrm{N}-\mathrm{H}$ bond distance being $1.60 \AA$ at the TS6, and this step was exothermic of $-0.40 \mathrm{eV}$. Energetically the most favourable paths have been summarized as the reactions 1 to 6 , with the main data shown in Table 1, and the scheme briefly depicted in Figure 5.

$$
\begin{gathered}
\mathrm{C}_{6} \mathrm{H}_{5} \mathrm{NOH}^{*}+\mathrm{H}^{*} \rightarrow \mathrm{C}_{6} \mathrm{H}_{5} \mathrm{NHOH}^{*} \\
\mathrm{C}_{6} \mathrm{H}_{5} \mathrm{NHOH}^{*} \rightarrow \mathrm{C}_{6} \mathrm{H}_{5} \mathrm{NH}^{*}+\mathrm{OH}^{*} \\
\mathrm{C}_{6} \mathrm{H}_{5} \mathrm{NH}^{*}+\mathrm{H}^{*} \rightarrow \mathrm{C}_{6} \mathrm{H}_{5} \mathrm{NH}_{2}^{*}
\end{gathered}
$$

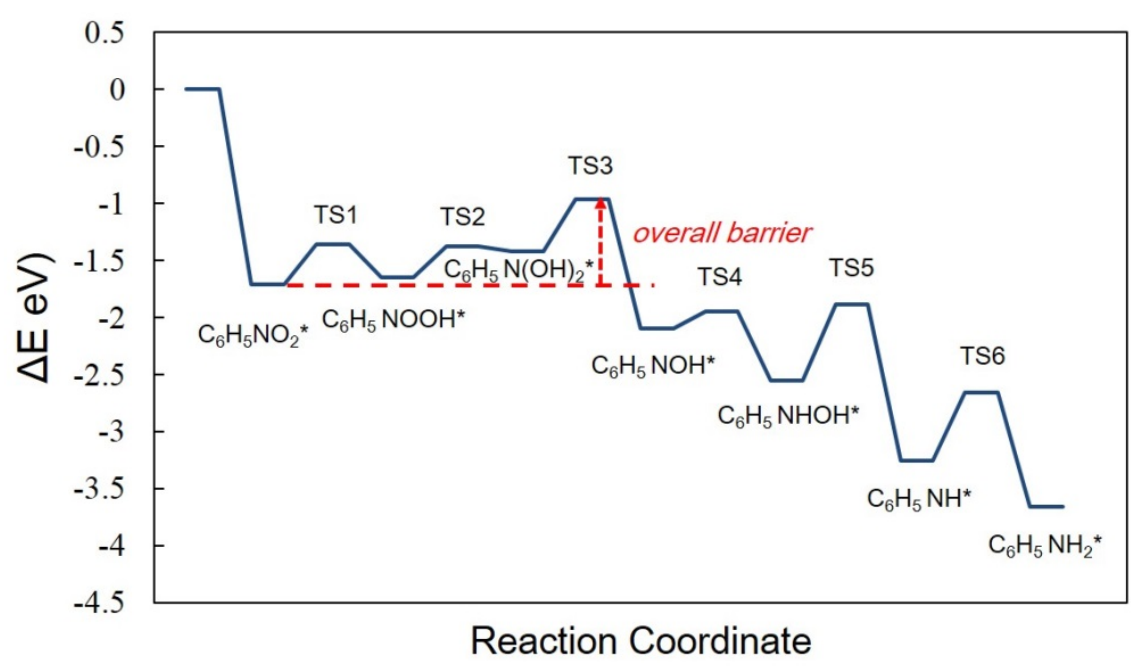

Fig. 3. Energy profiles for nitrobenzene reduction to aniline on $\operatorname{Pt}(111)$. 

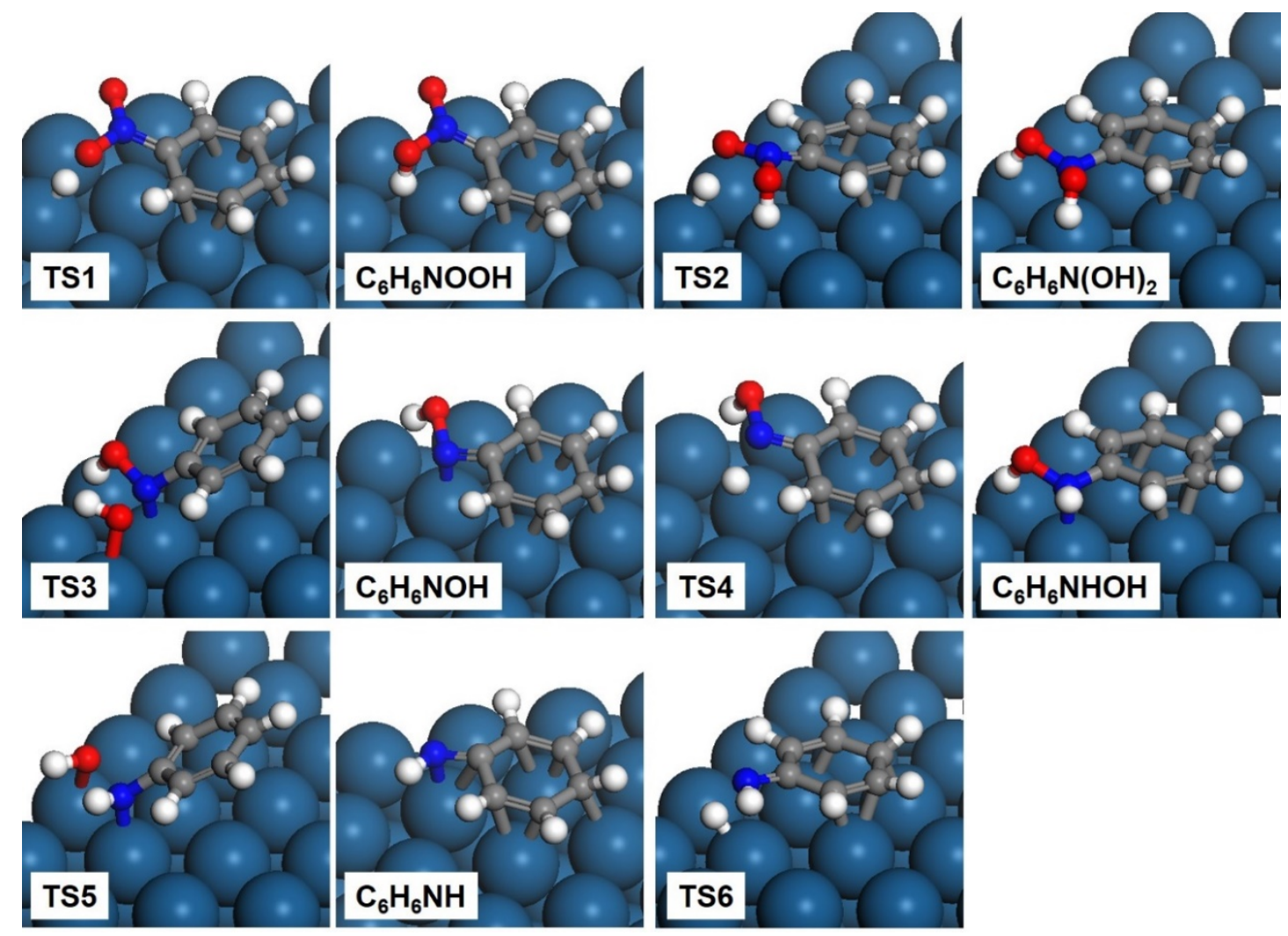

Fig. 4. Optimized structures of the intermediates and transition states in the nitrobenzene reduction to aniline on $\mathrm{Pt}(111)$. TS1 is the transition state of $\mathrm{C}_{6} \mathrm{H}_{5} \mathrm{NO}_{2} *+\mathrm{H}^{*} \rightarrow \mathrm{C}_{6} \mathrm{H}_{5} \mathrm{NOOH}^{*}$; TS2: $\mathrm{C}_{6} \mathrm{H}_{5} \mathrm{NOOH}^{*}$ $+\mathrm{H}^{*} \rightarrow \mathrm{C}_{6} \mathrm{H}_{5} \mathrm{~N}(\mathrm{OH})_{2} *$; TS3: $\mathrm{C}_{6} \mathrm{H}_{5} \mathrm{~N}(\mathrm{OH})_{2}{ }^{*} \rightarrow \mathrm{C}_{6} \mathrm{H}_{5} \mathrm{NOH}^{*}+\mathrm{OH}^{*} ;$ TS4: $\mathrm{C}_{6} \mathrm{H}_{5} \mathrm{NOH}^{*}+\mathrm{H}^{*} \rightarrow$ $\mathrm{C}_{6} \mathrm{H}_{5} \mathrm{NHOH}^{*}$; TS5: $\mathrm{C}_{6} \mathrm{H}_{5} \mathrm{NHOH}^{*} \rightarrow \mathrm{C}_{6} \mathrm{H}_{5} \mathrm{NH}^{*}+\mathrm{OH}^{*}$; TS6: $\mathrm{C}_{6} \mathrm{H}_{5} \mathrm{NH}^{*}+\mathrm{H}^{*} \rightarrow \mathrm{C}_{6} \mathrm{H}_{5} \mathrm{NH}_{2} *$.
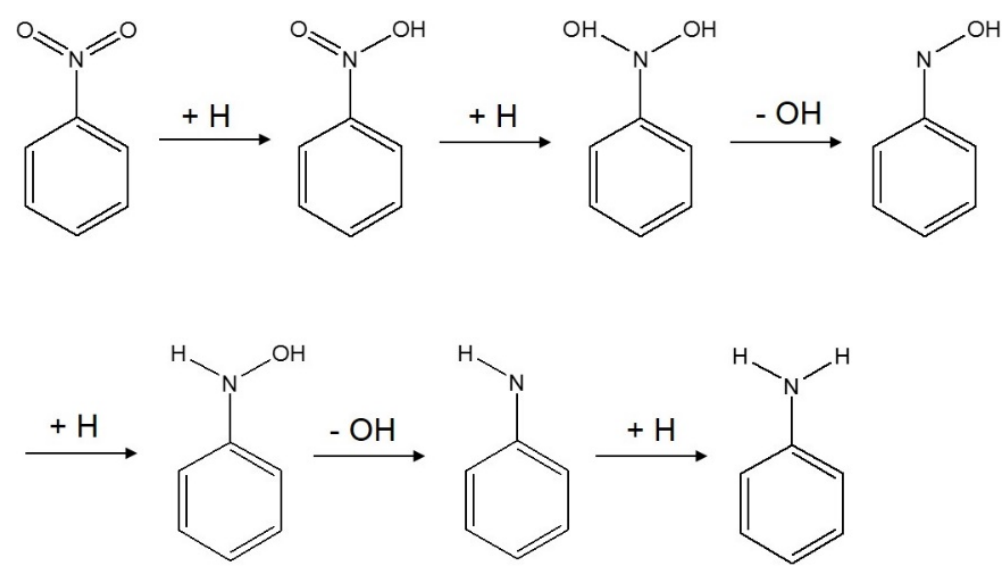

Fig. 5. Illustration of the overall mechanism of nitrobenzene reduction to aniline on $\operatorname{Pt}(111)$. 
Table 1. Calculated reaction barriers $\left(E_{a}\right.$, in $\left.e V\right)$ and reaction energies $(\Delta E$, in $e V)$ of the elementary steps involved in nitrobenzene reduction to aniline on $\mathrm{Pt}(111)$.

\begin{tabular}{ccc}
\hline Reactions & $\mathbf{E}_{\mathbf{a}}$ & $\boldsymbol{\Delta} \mathbf{E}$ \\
\hline $\mathrm{C}_{6} \mathrm{H}_{5} \mathrm{NO}_{2}{ }^{*}+\mathrm{H}^{*} \rightarrow \mathrm{C}_{6} \mathrm{H}_{5} \mathrm{NOOH}^{*}$ & 0.35 & 0.06 \\
$\mathrm{C}_{6} \mathrm{H}_{5} \mathrm{NOOH}^{*}+\mathrm{H}^{*} \rightarrow \mathrm{C}_{6} \mathrm{H}_{5} \mathrm{~N}(\mathrm{OH})_{2}{ }^{*}$ & 0.27 & 0.23 \\
$\mathrm{C}_{6} \mathrm{H}_{5} \mathrm{~N}(\mathrm{OH})_{2}{ }^{*} \rightarrow \mathrm{C}_{6} \mathrm{H}_{5} \mathrm{NOH}^{*}+\mathrm{OH}^{*}$ & 0.46 & -0.68 \\
$\mathrm{C}_{6} \mathrm{H}_{5} \mathrm{NOH}^{*}+\mathrm{H}^{*} \rightarrow \mathrm{C}_{6} \mathrm{H}_{5} \mathrm{NHOH}^{*}$ & 0.15 & -0.45 \\
$\mathrm{C}_{6} \mathrm{H}_{5} \mathrm{NHOH}^{*} \rightarrow \mathrm{C}_{6} \mathrm{H}_{5} \mathrm{NH}^{*}+\mathrm{OH}^{*}$ & 0.66 & -0.71 \\
$\mathrm{C}_{6} \mathrm{H}_{5} \mathrm{NH}^{*}+\mathrm{H}^{*} \rightarrow \mathrm{C}_{6} \mathrm{H}_{5} \mathrm{NH}_{2}{ }^{*}$ & 0.60 & -0.40 \\
\hline
\end{tabular}

\subsection{Influence of the adsorption of the phenyl group on reaction barriers}

An interesting phenomenon was observed during the search of the transition states, i.e., the adsorption/desorption of the phenyl group had significant impacts on the kinetic barrier. The latter was remarkable sensitive to the adsorption or desorption of the phenyl group. To better illustrate this issue, the reactions 2, 3, 4 and 5 were taken as examples which included hydrogenation ( $\mathrm{N}-\mathrm{H}$ or $\mathrm{O}-\mathrm{H}$ bond association) and deoxygenation (N-O bond dissociation) reactions. The energy profiles and the identified transition states are shown in Figures 6 and 7, respectively. In the energy profiles, the red line presents the favored reaction path. A comparison of calculated reaction barriers and bond distances between the two transition states is listed in Table 2.

Figure 6 shows that in the reaction 2, $\mathrm{C}_{6} \mathrm{H}_{5} \mathrm{NOOH}^{*}+\mathrm{H}^{*} \rightarrow \mathrm{C}_{6} \mathrm{H}_{5} \mathrm{~N}(\mathrm{OH})_{2}$, where an $\mathrm{O}-\mathrm{H}$ bond was formed, if the phenyl group adsorbed at the transition state via TS(ads) (Figure 6b), the barrier was $0.27 \mathrm{eV}$ with the $\mathrm{O}-\mathrm{H}$ bond distance of $1.43 \AA$. In contrast, if the phenyl group desorbed at the transition state via TS(des) (Figure 6c), the barrier would increase to $0.91 \mathrm{eV}$ with the $\mathrm{O}-\mathrm{H}$ bond distance being elongated to $1.70 \AA$ A. Similarly, in the hydrogenation of $\mathrm{C}_{6} \mathrm{H}_{5} \mathrm{NOH}^{*}$ to $\mathrm{C}_{6} \mathrm{H}_{5} \mathrm{NHOH}^{*}$ via formation of the $\mathrm{N}-\mathrm{H}$ bond in the reaction $4, \mathrm{C}_{6} \mathrm{H}_{5} \mathrm{NOH}^{*}+$ $\mathrm{H}^{*} \rightarrow \mathrm{C}_{6} \mathrm{H}_{5} \mathrm{NHOH}^{*}$, the barrier was $0.15 \mathrm{eV}$ at the TS(ads) (Figure 7b) but it would increase to $0.44 \mathrm{eV}$ at the TS(des) (Figure 7c). As well documented, the geometry of the surface 
structure generally plays a significant role at the transition state [44]. Herein, in order to better elucidate the issue, the contributions of the fragments $\left(\mathrm{C}_{6} \mathrm{H}_{5} \mathrm{NOOH}^{*}\right.$ and $\mathrm{H}^{*}$, respectively) to the total barrier were decomposed. It was found that at the TS(ads), the reactive $\mathrm{H}^{*}$ migrated from the fcc site to the top site with the $\mathrm{H}$-Pt bond distance of $1.71 \AA$, the energy barrier was $0.45 \mathrm{eV}$; whilst at the TS(des), the H-Pt distance was shorten to $1.59 \AA$, indicating that $\mathrm{H}^{*}$ was closer to the stable top site at which the $\mathrm{H}$-Pt distance was $1.56 \AA$, the barrier decreased to $0.28 \mathrm{eV}$ at the TS(des), which is significantly lower than that $(0.45 \mathrm{eV})$ at the TS(ads). With respect to the $\mathrm{C}_{6} \mathrm{H}_{5} \mathrm{NOOH}^{*}$ fragment, its movement to the TS(ads) position was facile with only a small barrier of $0.18 \mathrm{eV}$, whilst for its movement to the $\mathrm{TS}($ des), a significant barrier of $0.70 \mathrm{eV}$ was encountered. As aforementioned, desorption of phenyl group could cause the partial loss of chemisorption energy resulting in the fragment at the TS(des) being less stable than at the TS(ads). As a consequence, the main reason of the higher barrier provided by the TS(des) than TS(ads) could be the destabilization of $\mathrm{C}_{6} \mathrm{H}_{5} \mathrm{NOOH}^{*}$ fragment $(0.52 \mathrm{eV})$, even though $\mathrm{H}^{*}$ fragment was stabilized $(-0.17 \mathrm{eV})$ by the $\mathrm{TS}$ (des) rather than TS(ads). That is, at the TS(des), the stabilization from $\mathrm{H}^{*}$ of $-0.17 \mathrm{eV}$ could not compensate for the destabilization from $\mathrm{C}_{6} \mathrm{H}_{5} \mathrm{NOOH}^{*}$ of $0.52 \mathrm{eV}$. From this analysis, it is clear that the reaction via the TS(ads) would have the kinetic advantage over that via the TS(des) in the hydrogenation process.

On the other hand, in the reaction $3, \mathrm{C}_{6} \mathrm{H}_{5} \mathrm{~N}(\mathrm{OH})_{2} * \rightarrow \mathrm{C}_{6} \mathrm{H}_{5} \mathrm{NOH}^{*}+\mathrm{OH}^{*}$, the $\mathrm{N}-\mathrm{O}$ bond dissociation occurred. Differently from that in the hydrogenation process stated above, TS(des) was more energetically favoured over the TS(ads). To explain this point fully, the details are that if the TS(ads) (Figure 6d) was followed, the dissociation barrier would be $0.91 \mathrm{eV}$ with the N-O bond length of $2.16 \AA$; while if the TS(des) (Figure 6e) was the case, the barrier would be noticeably lowered to $0.46 \mathrm{eV}$ with the N-O bond distance of $1.73 \AA$. Therefore it is not unreasonable to propose that the adsorbed phenyl group in $\mathrm{C}_{6} \mathrm{H}_{5} \mathrm{~N}(\mathrm{OH})_{2}$ * was likely to desorb from surface transiently from the bri $30^{\circ}$ site as the TS(des), but once the dissociation completed, the phenyl group would adsorb back at the bri $30^{\circ}$ site again. And in the reaction $5, \mathrm{C}_{6} \mathrm{H}_{5} \mathrm{NHOH}^{*} \rightarrow \mathrm{C}_{6} \mathrm{H}_{5} \mathrm{NH}^{*}+\mathrm{OH}^{*}$, a similar result was obtained where the TS(des) (Figure 7d) could provide a much lower activation energy $(0.66 \mathrm{eV})$ than the TS(ads) 
(Figure 7e) would do $(0.89 \mathrm{eV})$. Through the analysis of the structures of TS(ads) and $\mathrm{TS}$ (des) in the reaction 3 , it was found that the thermodynamic stability of dissociating $\mathrm{OH}^{*}$ was the dominant factor. At the TS(ads), the O-Pt distance was elongated to $2.94 \AA$, which is extremely long in comparison with the O-Pt bond length of $1.99 \AA$ at the most stable adsorption site (top). Such a significant increase in the O-Pt bond distance strongly indicates that the $\mathrm{OH}^{*}$ would hardly be effectively stabilized by the Pt surface atom and as a result, the corresponding adsorption energy was $1.86 \mathrm{eV}$ higher than that at the top site. In contrast, at the TS(des), the O-Pt distance was decreased to $2.35 \AA$ which is closer to the most stable top site of $1.99 \AA$, resulting in a weak destabilization of $0.54 \mathrm{eV}$, which is much lower than that at the TS(ads). With respect to $\mathrm{C}_{6} \mathrm{H}_{5} \mathrm{NOH}^{*}$ fragment, the energy was close to the hydrogenation step in the reaction 2 as stated above. The movement of the phenyl group to $\mathrm{TS}$ (des) would require a high activation energy of $0.82 \mathrm{eV}$, but to TS(ads), $0.25 \mathrm{eV}$ would be sufficient. Although TS(ads) could stabilize the phenyl group more effectively than TS(des) with $0.57 \mathrm{eV}$, TS(ads) would provide a much weaker binding energy of dissociating $\mathrm{OH}^{*}$ (with $1.86 \mathrm{eV}$ ) than $\mathrm{TS}($ des$)$. It was clearly evidenced that the binding energy of $\mathrm{OH}^{*}$ governed the total barrier and as a result, the TS(des) had the kinetic advantage over the $\mathrm{TS}(a d s)$ in the deoxygenation process because of the stabilization of $\mathrm{OH}^{*}$.

Taking into account all the above results, the influence of the adsorption of the phenyl group could be summarized as follows: (i) in hydrogenation process ( $\mathrm{N}-\mathrm{H}$ or $\mathrm{O}-\mathrm{H}$ bond association), the phenyl group preferred to adsorb on the surface and the barrier was mainly determined by the adsorption of phenyl group since the adsorbed phenyl group could effectively decrease the barrier; (ii) in deoxygenation process (N-O bond dissociation), the phenyl group preferred to desorb transiently for stabilizing the dissociating $\mathrm{OH}^{*}$ which determined the total barrier. Nevertheless, in the whole reaction process, the phenyl group was predominately adsorbed on the surface throughout the reactions. 

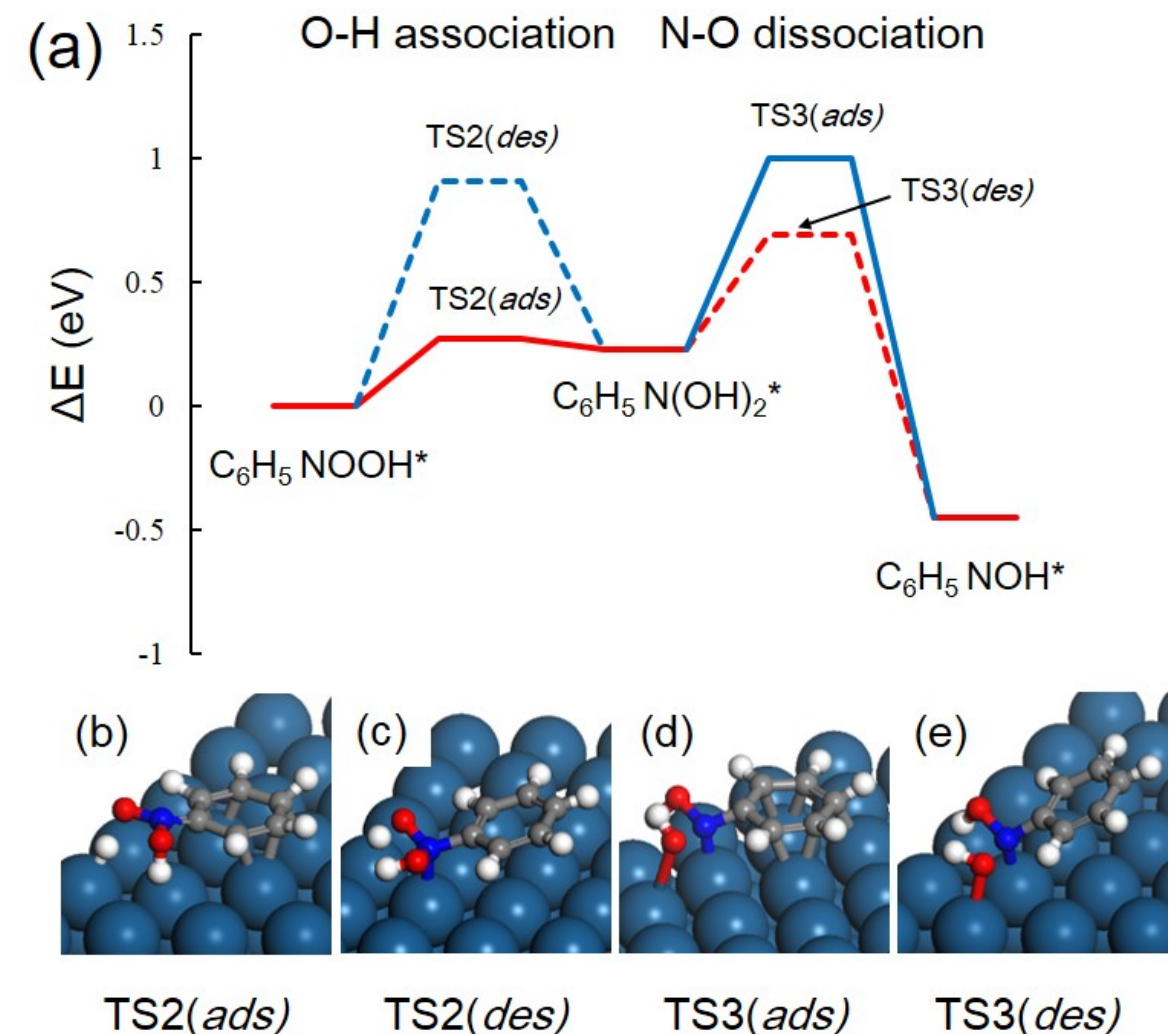

Fig. 6. Energy profiles (a) and structures of the 4 transition states (b-e) of the two step reactions: (i) $\mathrm{C}_{6} \mathrm{H}_{5} \mathrm{NOOH}^{*}+\mathrm{H}^{*} \rightarrow \mathrm{C}_{6} \mathrm{H}_{5} \mathrm{~N}(\mathrm{OH})_{2}{ }^{*}$ involving the $\mathrm{O}-\mathrm{H}$ bond association at the TS2; (ii) $\mathrm{C}_{6} \mathrm{H}_{5} \mathrm{~N}(\mathrm{OH})_{2} * \rightarrow \mathrm{C}_{6} \mathrm{H}_{5} \mathrm{NOH}^{*}+\mathrm{OH}^{*}$ involving the $\mathrm{N}-\mathrm{O}$ bond dissociation at the TS3. The solid line represents the adsorbed phenyl group at the transition states, TS(ads), and the dashed line represents the desorbed phenyl group at the transition states, TS(des). The red line presents the energetically favourable reaction path and the blue line represents the unfavourable path. (The same lines are used in Figure 7.) 


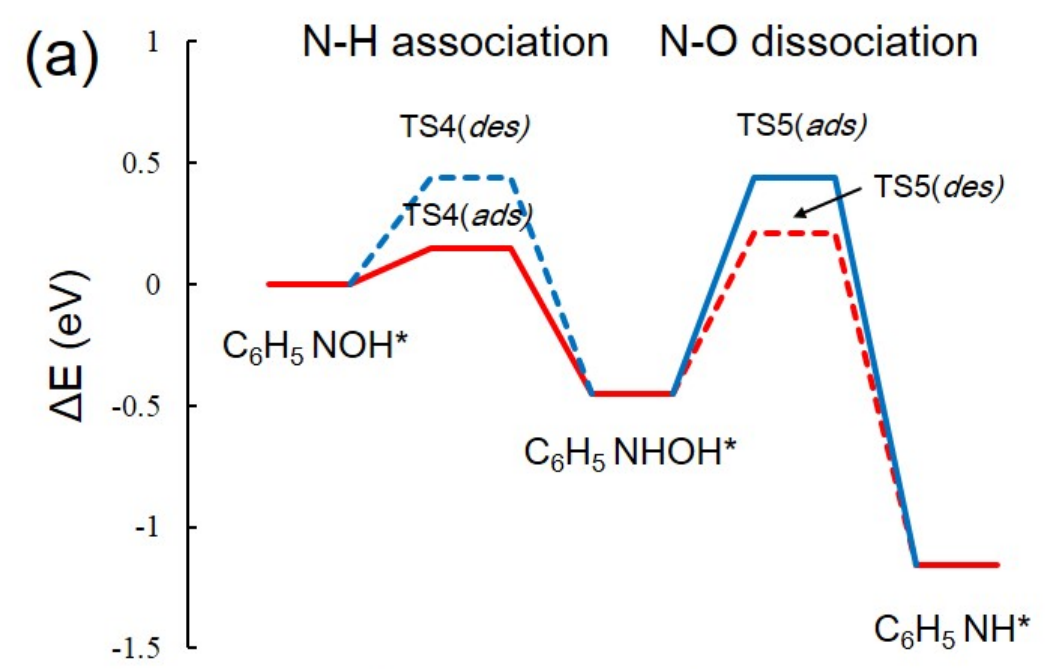

(b)

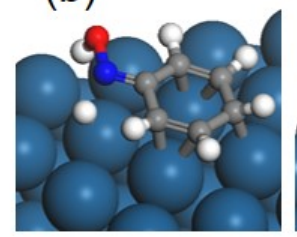

TS4(ads) (c)

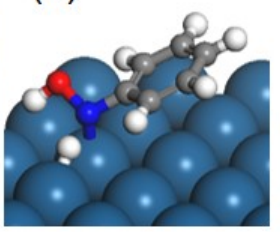

TS4(des) (d)

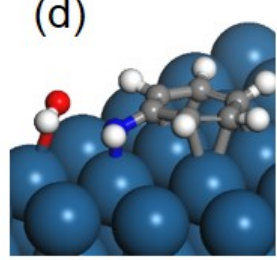

TS5(ads)

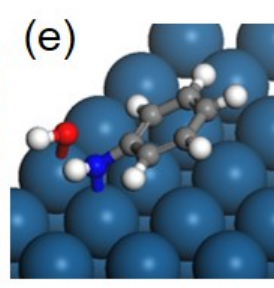

TS5(des)

Fig. 7. Energy profiles (a) and structures of the 4 transition states (b-e) of the two step reactions: (i) $\mathrm{C}_{6} \mathrm{H}_{5} \mathrm{NOH}^{*}+\mathrm{H}^{*} \rightarrow \mathrm{C}_{6} \mathrm{H}_{5} \mathrm{NHOH}^{*}$ involving the $\mathrm{N}-\mathrm{H}$ bond association at the TS4; (ii) $\mathrm{C}_{6} \mathrm{H}_{5} \mathrm{NHOH}^{*}$ $\rightarrow \mathrm{C}_{6} \mathrm{H}_{5} \mathrm{NH}^{*}+\mathrm{OH}^{*}$ involving the $\mathrm{N}-\mathrm{O}$ bond dissociation at the TS5.

Table 2. Comparison of the calculated reaction barriers $\left(E_{a}\right.$, in $\left.e V\right)$ and the bond distance (d, in $\AA$ ) between the adsorbed transition state, TS(ads), and the desorbed transition state, TS(des), in the reactions 2, 3, 4 and 5 of the nitrobenzene reduction to aniline on $\operatorname{Pt}(111)$.

\begin{tabular}{ccccc}
\hline Reactions & $\begin{array}{c}\mathbf{E}_{\mathbf{a}} \\
(\boldsymbol{a d s})\end{array}$ & $\mathbf{d}$ & $\begin{array}{c}\mathbf{E}_{\mathbf{a}} \\
(\boldsymbol{d e s})\end{array}$ & $\mathbf{d}$ \\
\hline $\mathrm{C}_{6} \mathrm{H}_{5} \mathrm{NOOH}^{*}+\mathrm{H}^{*} \rightarrow \mathrm{C}_{6} \mathrm{H}_{5} \mathrm{~N}(\mathrm{OH})_{2}{ }^{*}$ & 0.27 & 1.43 & 0.91 & 1.70 \\
$\mathrm{C}_{6} \mathrm{H}_{5} \mathrm{~N}(\mathrm{OH})_{2}^{*} \rightarrow \mathrm{C}_{6} \mathrm{H}_{5} \mathrm{NOH}^{*}+\mathrm{OH}^{*}$ & 0.77 & 2.16 & 0.46 & 1.73 \\
$\mathrm{C}_{6} \mathrm{H}_{5} \mathrm{NOH}^{*}+\mathrm{H}^{*} \rightarrow \mathrm{C}_{6} \mathrm{H}_{5} \mathrm{NHOH}^{*}$ & 0.15 & 1.57 & 0.44 & 1.55 \\
$\mathrm{C}_{6} \mathrm{H}_{5} \mathrm{NHOH}^{*} \rightarrow \mathrm{C}_{6} \mathrm{H}_{5} \mathrm{NH}^{*}+\mathrm{OH}^{*}$ & 0.89 & 2.02 & 0.66 & 1.78 \\
\hline
\end{tabular}


Selective catalysis of the desired functional group of aromatic molecules is a significant issue and it often depends strongly on the behavior of kinetics. To get an insight into the fact that, in the nitrobenzene reduction to aniline over Pt catalysts the benzene ring was not reduced by $\mathrm{H}^{*}$ attacking, we noted from our calculations that, the overall barrier for the reduction of nitrobenzene to aniline as highlighted in Figure 3 was $0.75 \mathrm{eV}$, which suggests that the reaction (nitrobenzene to aniline) is a feasible process at the room temperature. However, the overall barrier for the hydrogenation of benzene was remarkably high as $1.08 \mathrm{eV}$ [22]. From these data, it could be estimated that the reduction reaction rate of nitro- group is $\sim 10^{5}$ times higher than that of the phenyl group, according to the Arrhenius equation, $r=A e^{-E a / R T}$, at the room temperature $(\mathrm{T}=300 \mathrm{~K})$. Therefore, at the presence of nitro- group during the nitrobenzene reduction, $\mathrm{H}^{*}$ was consumed rapidly by the nitro reduction to yield aniline, but no excess $\mathrm{H}^{*}$ to be utilized for the hydrogenation of phenyl group. This knowledge may further suggest that, to control the selectivity towards different reactions concerning nitro aromatic molecules, such as the selectivity between the dehalogenation and hydrogenation of halo-nitrobenzene, the intrinsic reactivity of the functional group is highly important.

\section{Conclusion}

The mechanism of nitrobenzene reduction to aniline over $\operatorname{Pt}(111)$ catalyst has been systematically investigated using first principles calculation with the inclusion of the vdW interaction. The overall mechanism has been identified as $\mathrm{C}_{6} \mathrm{H}_{5} \mathrm{NO}_{2} * \rightarrow \mathrm{C}_{6} \mathrm{H}_{5} \mathrm{NOOH}^{*} \rightarrow$ $\mathrm{C}_{6} \mathrm{H}_{5} \mathrm{~N}(\mathrm{OH})_{2}{ }^{*} \rightarrow \mathrm{C}_{6} \mathrm{H}_{5} \mathrm{NOH}^{*} \rightarrow \mathrm{C}_{6} \mathrm{H}_{5} \mathrm{NHOH}^{*} \rightarrow \mathrm{C}_{6} \mathrm{H}_{5} \mathrm{NH}^{*} \rightarrow \mathrm{C}_{6} \mathrm{H}_{5} \mathrm{NH}_{2} *$ In addition, the following conclusions have been obtained.

(1) For the initial N-O bond dissociation, double H-induced path was identified as the most favourable reaction route for activating and reducing the $-\mathrm{NO}_{2}$ group to $-\mathrm{N}(\mathrm{OH})_{2}$ group, resulting in the lowest $\mathrm{N}-\mathrm{O}$ bond dissociation barrier of $0.46 \mathrm{eV}$, in comparison with the direct dissociation path $\left(\mathrm{E}_{\mathrm{a}}=1.51 \mathrm{eV}\right)$ and the single $\mathrm{H}$-induced dissociation path $\left(\mathrm{E}_{\mathrm{a}}=1.02\right.$ $\mathrm{eV})$.

(2) The adsorption/desorption of the phenyl group at the transition state was found to affect considerably the kinetic barrier. In general, with respect to the hydrogenation process $(\mathrm{N}-\mathrm{H}$ or $\mathrm{O}-\mathrm{H}$ bond association), the phenyl group adsorbed at the most stable bri30 $30^{\circ}$ site, but as to the 
deoxygenation (N-O bond dissociation), phenyl group desorbed transiently for facilitating the dissociation and then it adsorbed back on the bri30 $30^{\circ}$ site.

(3) The overall barrier for the nitrobenzene reduction to aniline was $0.75 \mathrm{eV}$, which is significantly lower than that of $1.08 \mathrm{eV}$ for the hydrogenation of benzene, suggesting that the rapid reduction of the nitro group would prohibit the reduction of the phenyl group, leading to the major product being aniline. This result coincides with the experimental data and further explains the selectivity issue from the kinetics point of view.

\section{Acknowledgements}

Financial support from the EPSRC (EP/I013229/1), as part of the RCUK Energy Programme, and the NSFC (21361140374 and 21321062) is acknowledged. X.L. thanks QUB for the award of the title of Visiting Research Associate.

\section{Reference}

(1) J. Marquez, D. Pletcher, A study of the electrochemical reduction of nitrobenzene to para-aminophenol, J. Appl. Electrochem. 10 (1980) 567-573.

(2) A. Cyr, P. Huot, J. F. Marcoux, G. Belot, E. Laviron, J. Lessard, The electrochemical reduction of nitrobenzene and azoxybenzene in neutral and basic aqueous methanolic solutions at polycrystalline copper and nickel electrodes, Electrochim. Acta 34 (1989) 439-445.

(3) T. R. Nolen, P. S. Fedkiw, Kinetic-study of the electroreduction of nitrobenzene, J. Appl. Electrochem. 20 (1990) 370-376.

(4) A. Cyr, P. Huot, G. Belot, J. Lessard, The efficient electrochemical reduction of nitrobenzene and azoxybenzene to aniline in neutral and basic aqueous methanolic solutions at devarda copper and raney-nickel electrodes - electrocatalytic hydrogenolysis of N-O and N-N bonds, Electrochim. Acta 35 (1990) 147-152.

(5) J. Jiang, R. Zhai, X. Bao, Electrocatalytic properties of Cu-Zr amorphous alloy towards the electrochemical hydrogenation of nitrobenzene, J. Alloys Compd. 354 (2003) 248-258.

(6) C. H. Li, Z. X. Yu, K. F. Yao, S. F. Ji, J. Liang, Nitrobenzene hydrogenation with carbon nanotube-supported platinum catalyst under mild conditions, J. Mol. Catal. A: Chem. 226 
(2005) 101-105.

(7) V. R. C. Komandur, S. S. Chakravartula, Selective hydrogenation of nitrobenzene to aniline over Ru/SBA-15 catalysts, Catal. Lett. 128 (2009) 164-170.

(8) S. Diao, W. Qian, G. Luo, F. Wei, Y. Wang, Gaseous catalytic hydrogenation of nitrobenzene to aniline in a two-stage fluidized bed reactor, Appl. Catal., A: General 286 (2005) 30-35.

(9) X. Meng, H. Cheng, Y. Akiyama, Y. Hao, W. Qiao, Y. Yu, F. Zhao, S. Fujita, M. Arai, Selective hydrogenation of nitrobenzene to aniline in dense phase carbon dioxide over Ni/gamma- $\mathrm{Al}_{2} \mathrm{O}_{3}$ : Significance of molecular interactions, J. Catal. 264 (2009) 1-10.

(10) F. Zhao. Y. Ikushima, M. Arai, Hydrogenation of nitrobenzene with supported platinum catalysts in supercritical carbon dioxide: effects of pressure, solvent and metal particle size, J. Catal. 224 (2004) 479-483.

(11) F. Y. Tian, Y. X. Cui, A. V. Teplyakov, Nitroxidation of H-terminated Si(111) surfaces with nitrobenzene and nitrosobenzene, J. Phys. Chem. C 118 (2014) 502-512.

(12) E. A. Gelder, S. D. Jackson, C. M. Lok, The hydrogenation of nitrobenzene to aniline: a new mechanism, Chem. Comm. 4 (2005) 522-524.

(13) A. Corma, P. Concepcion, P. Serna, A different reaction pathway for the reduction of aromatic nitro compounds on gold catalysts, Angew. Chem. Int. Ed. 46 (2007) 7266-7269.

(14) J. Marquez, D. Pletcher, The cathodic reduction of ortho-halonitrobenzenes in acidic propanol-water, Electrochim. Acta 26 (1981) 1751-1754.

(15) V. Kratky, M. Kralik, M. Mecarova, M. Stolcova, L. Zalibera, M. Hronec, Effect of catalyst and substituents on the hydrogenation of chloronnitrobenzenes, Appl. Catal., A: General 235 (2002) 225-231.

(16) B. Coq, A. Tijani, F. Figueras, Particle-size effect on the kinetics of p-chloronnitrobenzene hydrogenation over platinum alumina catalysts, J. Mol. Catal. 68 (1991) 331-345.

(17) F. Cardenas-Lizana, S. Gomez-Quero, M. A. Keane, Clean production of chloronilines by selective gas phase hydrogenation over supported Ni catalysts, Appl. Catal., A: General 334 (2008) 199-206.

(18) M. H. Liang, X. D. Wang, H. Q. Liu, H.C. Liu, Y. Wang, Excellent catalytic properties 
over nanocomposite catalysts for selective hydrogenation of halonitrobenzenes, J. Catal. 255 (2008) 335-342.

(19) J. Lyu, J. Wang, C. Lu, L. Ma, Q. Zhang, X. He, X. Li, Size-dependent halogenated nitrobenzene hydrogenation selectivity of Pd nanoparticles, J. Phys. Chem. C 118 (2014) 2594-2601.

(20) R. K. Rai, A. Mahata, S. Mukhopahyay, S. Gupta, P. Z. Li, K. T. Nguyen, Y. Zhao, B. Pathak, S. K. Singh, Room-temperature chemoselective reduction of nitro groups using non-noble metal nanocatalysts in water, Inorg. Chem. 53 (2014) 2904-2909.

(21) M. Saeys, M. F. Reyniers, G. B. Marin, M. Neurock, Density functional study of benzene adsorption on Pt(111), J. Phys. Chem. B 106 (2002) 7489-7498.

(22) M. Saeys, M. F. Reyniers, M. Neurock, G. B. Marin, Ab initio reaction path analysis of benzene hydrogenation to cyclohexane on Pt(111), J. Phys. Chem. B 109 (2005) 2064-2073.

(23) W. Liu, J. Carrasco, B. Santra, A. Michaelides, M. Scheffler, A. Tkatchenko, Benzene adsorbed on metals: Concerted effect of covalency and van der Waals bonding, Phys. Rev. B 86 (2012) 245405.

(24) J. Klimes, D. R. Bowler, A. Michaelides, Chemical accuracy for the van der Waals density functional, J. Phys.: Cond Matt. 22 (2010) 022201.

(25) J. Klimes, D. R. Bowler, A. Michelides, Van der Waals density functionals applied to solids, Phys. Rev. B. 83 (2011) 195131.

(26) A. Mahata, R. K. Rai, I. Choudhuri, S. K. Singh, B. Pathak, Direct vs indirect pathway for nitrobenzene reduction reaction on a Ni catalyst surface: a density functional study, Phys. Chem. Chem. Phys. 16 (2014) 26365-26374.

(27) L. B. Zhao, Y. F. Huang, X. N. Liu, J. R. Anema, D. Y. Wu, B. Ren, Z. Q. Tian, A DFT study on photoinduced surface catalytic coupling reactions on nanostructured silver: selective formation of azobenzene derivatives from para-substituted nitrobenzene and aniline, Phys. Chem. Chem. Phys. 14 (2012) 12919-12929.

(28) J. Lu, S. Behtash, O. Mamun, A. Heyden, Theoretical investigation of the reaction mechanism of the guaiacol hydrogenation over a $\operatorname{Pt}(111)$ catalyst, ACS Catal. 5 (2015) 2423-2435.

(29) J. Lu, A. Heyden, Theoretical investigation of the decarboxylation and decarbonylation 
mechanism of propanoic acid over a Ru(0001) model surface, J. Catal. 321 (2015) 39-50.

(30) S. Wang, V. Vorotnikov, G. D. Vlachos, Coverage-induced conformational effects on activity and selectivity: hydrogenation and decarbonylation of furfural on $\operatorname{Pd}(111)$, ACS Catal. 5 (2015) 104-112.

(31) S. Wang, V. Vorotnikov, J. E. Sutton, D. G. Vlachos, Bronsted-evans-polanyi and transition state scaling relations of furan derivatives on $\operatorname{Pd}(111)$ and their relation to those of small molecules, ACS Catal. 4 (2014) 604-612.

(32) L. Zhang, J. Jiang, W. Shi, S. Xia, Z. Ni, X. Xiao, Insights into the hydrogenation mechanism of nitrobenzene to aniline on $\mathrm{Pd}_{3} / \mathrm{Pt}(111)$ : a density functional theory study, RSC Adv., 5 (2015) 34319-34326.

(33) G. Kresse, J. Hafner, Ab initio molecular dynamics for open-shell transition metals, Phys. Rev. B. 48 (1993) 13115-13118.

(34) G. Kresse, J. Furthmuler, Efficient iterative schemes for ab initio total-energy calculations using a plane-wave basis set, Phys. Rev. B 54 (1996) 11169-11186.

(35) G. Kresse, J. Hafner, Ab initio molecular-dynamics for liquid metals, Phys. Rev. B 47 (1993) 558-561.

(36) G. Kresse, J. Hafnre, Ab initio molecular-dynamics simulation of the liquid-metal amorphous-semiconductor transition in germanium, Phys. Rev. B 49 (1994) 14251-14269.

(37) G. Kresse, J. Furthmuller, Efficiency of ab-initio total energy calculations for metals and semiconductors using a plane-wave basis set, Comput. Mater. Sci. 6 (1996) 15-50.

(38) P. E. Blochl, Projector augmented-wave method, Phys. Rev. B 50 (1994) 17953-17979.

(39) G. Kresse, D. Joubert, From ultrasoft pseudopotentials to the projector augmented-wave method, Phys. Rev. B 59 (1999) 1758-1775.

(40) A. Wander, G. Held, R. Q. Hwang, G. S. Blackman, M. L. Xu, P. de Andres, M. A. Van Hove, G. A. Somorjai, A diffuse leed study of the adsorption structure of disordered benzene on Pt(111), Surf. Sci. 249 (1991) 21-34.

(41) P. S. Weiss, D. M. Eigler, Site dependence of the apparent shape of a molecule in scanning tunneling microscope images-benzene on Pt(111), Phys. Rev. Lett. 71 (1993) 3139-3142.

(42) A. Alavi, P. Hu, T. Deutsch, P. L. Silvestrelli, J. Hutter, CO oxidation on Pt(111): an ab 
initio density functional theory study, Phys. Rev. Lett. 80 (1998) 3650-3653.

(43) A. Michadelides, Z. P. Liu, C. J. Zhang, A. Alavi, D. A. King, P. Hu, Identification of general linear relationships between activation energies and enthalpy changes for dissociation reactions at surfaces, J. Am. Chem. Soc. 125 (2003) 3704-3705.

(44) Z. P. Liu, P. Hu, General rules for predicting where a catalytic reaction should occur on metal surfaces: a density functional theory study of $\mathrm{C}-\mathrm{H}$ and $\mathrm{C}-\mathrm{O}$ bond breaking/making on flat, stepped and kinked metal surfaces, J. Am. Chem. Soc. 125 (2003) 1958-1967.

(45) X. M. Cao, R. Burch, C. Hardacre, P. Hu, Density functional theory study on the cleavage mechanism of the carbonyl bond in amides on flat and stepped $\mathrm{Ru}$ surfaces: hydrogen-induced or direct C-O bond breaking? J. Phys. Chem. C 116 (2012) 18713-18721.

(46) B. T. Loveless, C. Buda, M. Neurock, E. Iglesia, CO chemisorption and dissociation at high coverages during CO hydrogenation on Ru catalysts, J. Am. Chem. Soc. 135 (2013) 6107-6121. 